\title{
IMPLEMENTASI PENGELOLAAN AIRTANAH BERBASIS METODE KONSERVASI DI BUKIT BADUNG, KECAMATAN KUTA SELATAN
}

\author{
Gusti Ayu Rosita, Putu Indra Christiawan, Sutarjo \\ Jurusan Pendidikan Geografi \\ Universitas Pendidikan Ganesha \\ Singaraja, Indonesia
}

e-mail: ayurositaa@yahoo.com , putuic87@gmail.com , sutario1952@yahoo.com

\begin{abstract}
Abstrak
Penelitian ini dilaksanakan di Kecamatan Kuta Selatan dengan tujuan: (1). menganalisis kualitas airtanah di Bukit Badung, Kecamatan Kuta Selatan. (2). menganalisis bentuk pengelolaan airtanah berbasis metode konservasi di Bukit Badung, Kecamatan Kuta Selatan. (3). menganalisis kendala dalam pengelolaan airtanah berbasis metode konservasi di Bukit Badung, Kecamatan Kuta Selatan. Penelitian ini dirancang sebagai penelitian deskriptif dengan sampel 10\% dari populasi sebesar 862 yang diambil secara Proposional Random Sampling (86) dan sampel areal 3 wilayah yang diambil secara purposive sampling. Pengumpulan data primer menggunakan metode observasi, metode wawancara terstruktur, metode analisis laboratorium dan sekunder menggunakan pencatatan dokumen, yang selanjutnya dianalisis dengan metode deskriptif kualitatif.

Hasil penelitian menunjukkan bahwa (1). kualitas airtanah Kecamatan Kuta Selatan tergolong tinggi yang ditentukan oleh parameter fisik dan kimia (2). bentuk pengelolaan airtanah di Kecamatan Kuta Selatan didominasi oleh bentuk pengelolaan dengan teknik vegetasi. (3). kendala utama dalam pengelolaan airtanah adalah kendala ekonomi.
\end{abstract}

Kata kunci: Kualitas airtanah, metode konservasi, kendala pengelolaan airtanah

\begin{abstract}
This research was conducted in South Kuta District with the aim is to: (1). analyze the quality of groundwater in Bukit Badung, South Kuta District. (2). analyze the form of groundwater management based on conservation method and 3). analyzed constraint in groundwater management based on conservation methods in Bukit Badung, Kecamatan Kuta Selatan. This study was designed as a descriptive study with sampel (10\%), from a population of 862 were taken by Proposional Random Sampling and samples of 3 area areas taken by Purposive Sampling. Primary data collection using observation method of structured interview method, laboratory analysis method and secondary using document recording, which then analyzed by using qualitative descriptive method. The results showed that (1). the quality of groundwater of South Kuta District is high, determined by physical and chemical parameters (2). the form of groundwater management in Kecamatan Kuta Selatan is dominated by the management of vegetation techniques. (3). the main constraint in groundwater management is economic constraint.

Keywords: Groundwater quality, conservation methods, landwater management constraint.
\end{abstract}




\section{PENDAHULUAN}

Air merupakan kebutuhan pokok bagi makhluk hidup di bumi ini. Air bersih maupun air minum harus memenuhi syarat fisik, kimia, mikrobiologi dan radioaktif). Kualitas air harus tetap baik sehingga dapat dimanfaatkan secara berkelanjutan sesuai dengan tingkat mutu air yang diinginkan, maka perlu upaya pelestarian dan pengendalian air.

Bali merupakan salah satu pulau yang terpadat di Indonesia yang kebutuhan air di suplay oleh PDAM. Kebutuhan air tidak bisa menjangkau seluruh penduduk di Bali, dilihat dari sumber air di Pulau Bali adalah dari air hujan, air sungai, air danau, airtanah dan mata air.

Kabupaten Badung dengan kepadatan penduduk 1846,86 meningkat sepanjang tahun, kepadatan penduduk yang terus meningkat sementara luas wilayah tetap, akan cenderung memberikan dampak yang besar terhadap perubahan kualitas lingkungan khususnya lingkungan airtanah. Kebutuhan akan air selalu mengalami peningkatan sejalan dengan pertumbuhan penduduk untuk memanfaatkannya dalam berbagai kebutuhan rumah tangga, pertanian, industri.

Peningkatan

jumlah

penduduk serta kemajuan teknologi secara pesat terutama di bidang industri dan pariwisata yang menuntut kebutuhan air yang semakin meningkat pula. Sumber air yang dipergunakan oleh penduduk untuk keperluan sehari-hari (mandi, cuci) dan keperluan industri bersumber dari airtanah dan air PDAM.

Berdasarkan penelitian Sundra (2012) yang meneliti kualitas

\section{METODE}

Penelitian ini dilakukan di Kecamatan Kuta Selatan, Kabupaten Badung. Objek dalam airtanah di wilayah Bukit Badung menyatakan bahwa terdapat beberapa komponen yang melampaui baku mutu yang telah ditetapkan seperti: TDS, POSPAT, BOD, COD, coliform.

Kabupaten

Badung khususnya Kecamatan Kuta Selatan merupakan daerah pariwisata di Bali dan memiliki kepadatan penduduk yang tinggi dengan permasalahan sulitnya suplay air bersih oleh PDAM dan masyarakat banyak yang menggunakan air bawah tanah yang kebersihannya tidak sesuai baku mutu. Melihat permasalahan yang terjadi di Kecamatan Kuta Selatan dalam penelitian ini dilakukan "Implementasi pengelolaan airtanah berbasis metode konservasi di bukit Badung, Kecamatan Kuta selatan." Permasalahan pada penelitian ini (1) Bagaimana kualitas airtanah di Bukit Badung, Kecamatan Kuta Selatan, (2) Bagaimana bentuk pengelolaan airtanah berbasis metode konservasi di Bukit Badung, Kecamatan Kuta Selatan, (3) Bagaimana kendala dalam pelaksanaan pengelolaan airtanah berbasis metode konservasi di Bukit Badung, Kecamatan Kuta Selatan

Tujuan dari penelitian (1) Menganalisis kualitas airtanah di Bukit Badung, Kecamatan Kuta Selatan, (2) Menganalisis bentuk pengelolaan airtanah berbasis metode konservasi di Bukit Badung, Kecamatan Kuta Selatan (3) Menganalisis kendala dalam pengelolaan airtanah berbasis meode konservasi di Bukit Badung, Kecamatan Kuta Selatan.

penelitian ini airtanah yang dimanfaatkan di bukit Badung, Kecamatan Kuta selatan. 
Memperhatikan Objek Penelitian tersebut, yang menjadi subjek dalam penelitian ini adalah masyarakat yang menggunakan airtanah di Kecamatan Kuta Selatan, Kabupaten Badung. Penelitian ini menggunakan racangan penelitian deskriptif. Data yang digunakan adalah data primer dan sekunder.

\section{HASIL DAN PEMBAHASAN Kualitas airtanah Kecamatan Kuta Selatan}

Parameter fisik dan kimia merupakan parameter yang digunakan untuk mengetahui kualitas airtanah di Kecamatan Kuta Selatan, parameter fisik meliputi yaitu Rasa, Bau, Warna, Suhu. Paramter kimia meliputi Kesadahan, Nitrat, Nitrit, pH.Hasil pemeriksaan diberi nilai skor 1 untuk yang sesua
Data sekunder bersumber dari Badan Pusat statistik Kabupaten Badung. Data primer yang telah dikumpulkan selanjutnya akan dianalisis menggunakan analisis deskriptif kualitatif dengan menggunakan pendekatan keruangan. Kualitas airtanah ditinjau dari parameter fisik dan kimia.

Tabel 2. Hasil Kualitas Airtanah Kecamatan Kuta Selatan

\begin{tabular}{|c|c|c|c|c|c|}
\hline \multirow[t]{2}{*}{ No } & \multirow[t]{2}{*}{ Parameter } & \multirow{2}{*}{$\begin{array}{c}\text { Kadar } \\
\text { Maksimum } \\
\text { yang } \\
\text { diperbolehkan }\end{array}$} & \multicolumn{3}{|c|}{ Hasil Analisis } \\
\hline & & & ATTB & ATB & ATP \\
\hline (1) & (2) & (3) & (4) & (5) & (6) \\
\hline \multicolumn{6}{|c|}{ A. Fisik } \\
\hline 1. & $\mathrm{Bau}$ & Tidak berbau & Tidak berbau & Tidak berbau & Berbau \\
\hline 2. & Rasa & Tidak berasa & Tidak berasa & Tidak berasa & Tidak berasa \\
\hline 3. & Suhu & Suhu $30^{\circ} \mathrm{C}$ & 27,2 & 27,2 & 27,2 \\
\hline 4. & Warna & 50 & 10,648 & 5,291 & 12,409 \\
\hline \multicolumn{6}{|c|}{ B. Kimia } \\
\hline & Kesadahan $\left(\mathrm{CaC}_{3}\right)$ & 500 & 527,45 & 1229,25 & 89,40 \\
\hline & Nitrat $\left(\mathrm{No}_{3}-\mathrm{N}\right)$ & 10 & 2,395 & 1,953 & 1,124 \\
\hline & Nitrit $\left(\mathrm{NO}_{2}-\mathrm{N}\right)$ & 1,0 & 0,448 & 0,021 & $<0,001$ \\
\hline 8. & $\mathrm{Ph}$ & $6,5-9,0$ & 7,45 & 7,49 & 7,95 \\
\hline
\end{tabular}

Sumber: UPT Balai Laboratorium Kesehatan Provinsi Bali Tahun 2017

Ket:

ATTB: Airtanah Tanjung Benoa

ATB : Airtanah Benoa

ATP : Airtanah Pecatu

Berdasarkan Tabel 2 terlihat Hasil pengujian menunjukkan bahwa airtanah Kecamatan Kuta Selatan dari segi parameter fisika terdapat 1 parameter yang tidak sesuai dengan bakumutu yang sudah di tetapkan, yaitu parameter fisik dengan unsur bau yaitu terdapat di Desa Pecatu kualitas airtanah berbau. Parameter yang melapaui bakumutu yang sudah ditetapkan ini disebabkan oleh terjadinya pencemaran di Desa Pecatu. 
Hasil pengujian dari segi parameter kimia yaitu kesadahan, nirat, nitrat dan $\mathrm{pH}$, terdapat unsur yang tidak sesuai dengan baku muku yang ditetapkan Permenkes RI No. 492/Menkes/Per/IV/2010 yaitu Kesadahan di dua kelurahan yaitu Kelurahan Tanjung Benoa dan Benoa.

Parameter yang melapaui bakumutu kesadahan airtanah Kecamatan Kuta Selatan yang sudah ditetapkan bakumu ini disebabkan karena adanya ion-ion $\mathrm{Ca}^{2+}$ dan $\mathrm{Mg}^{2+}$ atau dapat juga disebabkan karena adanya ion-ion lain dari polyvalent

\section{Bentuk Pengelolaan Airtanah Berbasis Metode Konservasi}

Berdasarkan data yang diperoleh dengan metode observasi di lapangan terdapat tiga bentuk pengelolaan airtanah berbasis mental seperti Al. Fe, Mn, Sr dan Zn dalam bentuk garam sulfat, klorida dan bikarbonat dalam jumlah kecil.

Dibandingkan dengan penelitian sebelumnya, penelitian ini terdapat perbedaan mengenai parameter yang tidak sesuai dengan bakumutu yang sudah ditetapkan dengan penelitian yang dilakukan oleh I Ketut Sundra (2015) dan Widiyanti, N.L.P.M. (2017). Hasil penelitian menunjukkan bahwa kualitas airtanah Kuta Selatan total dari 20 parameter terdapat 4 parameter yang melapaui bakumutu.

metode konservasi yaitu, teknik vegetasi, teknik kimia dan teknik mekanik dapat dilihat pada Tabel 03 berikut.

Tabel 3. Bentuk Pengelolaan airtanah

\begin{tabular}{|c|c|c|c|c|c|c|c|c|c|}
\hline \multirow{2}{*}{ No } & \multirow{2}{*}{$\begin{array}{c}\text { Desa/ } \\
\text { Kelurahan }\end{array}$} & \multicolumn{3}{|c|}{ Bentuk Pengelolaan Airtanah Berbasis Metode Konservasi } \\
\cline { 3 - 10 } & & \multicolumn{2}{|c|}{ Vegetasi } & \multicolumn{2}{|c|}{ Kimia } & \multicolumn{2}{c|}{ Mekanik } & \multicolumn{2}{c|}{ Total } \\
\cline { 3 - 10 } & & $\mathrm{N}$ & $\%$ & $\mathrm{~N}$ & $\%$ & $\mathrm{~N}$ & $\%$ & $\mathrm{~N}$ & $\%$ \\
\hline$(1)$ & $(2)$ & $(3)$ & $(4)$ & $(5)$ & $(6)$ & $(7)$ & $(8)$ & $(9)$ & $(10)$ \\
\hline 1. & Tanjung Benoa & 23 & 47 & 9 & 18 & 17 & 35 & 49 & 100 \\
2. & Benoa & 25 & 44 & 13 & 23 & 19 & 33 & 57 & 100 \\
3. & Pecatu & 16 & 41 & 12 & 31 & 11 & 28 & 39 & 100 \\
& Jumlah & 64 & 44 & 34 & 23 & 47 & 32 & 145 & 100 \\
& & & & & & & &
\end{tabular}

Sumber: Data Primer, 2017

Berdasarkan Tabel 3 Hasil

penelitian menunjukkan bahwa bentuk pengelolaan airtanah terbesar di Kecamatan Kuta Selatan adalah teknik vegetasi sebesar $44 \%$. Bentuk pengelolaan airtanah terendah di Kecamatan Kuta Selatan adalah teknik kimia sebesar $24 \%$. Berikut diuraikan berdasarkan teknik

\section{Teknik Vegetasi}

Teknik vegetasi yang diterapkan di Kecamatan Kuta Selatan dapat dilihat dengan indikator yaitu, ketersedian lahan vegetasi, luas vegetasi, jenis vegetasi, jumlah tanaman, serta kondisi vegetasi.
Hasil penelitian menunjukkan bahwa bentuk pengelolaan airtanah berbasis konservasi dengan teknik vegetasi di Kecamatan Kuta Selatan rata-rata menggunakan teknik vegetasi memiliki vertikultur. Luas vegetasi yang dimiliki penduduk juga sangat sempit hanya seluas kurang dari $2 \times 1$ meter sampai dengan $3 \times 2$ meter, dengan luas lahan vegetasi yang dimiliki penduduk Kecamatan Kuta Selatan yang mendominasi yaitu tanaman hias. Kondisi vegetasi yang dimiliki penduduk Kecamatan Kuta Selatan kebanyakan terawat, tetapi tidak tertata dengan baik dan bersih. Perawatan vegetasi tidak terlalu intensif dilakukan oleh 
penduduk Kecamatan Kuta Selatan penggunaan pupuk dalam 1 bulan saja masih jarang-jarang digunakan, sehingga tidak memiliki pengaruh yang signifikan terhadap tanaman

Dibandingkan dengan
Selatan yang menerapkan teknik vegetasi dengan tersedia lahannya tidak menggunakan vertikultur menunjukkan bahwa memiliki pengaruh terhadap pengelolaan airtanah.

penduduk di Kecamatan Kuta

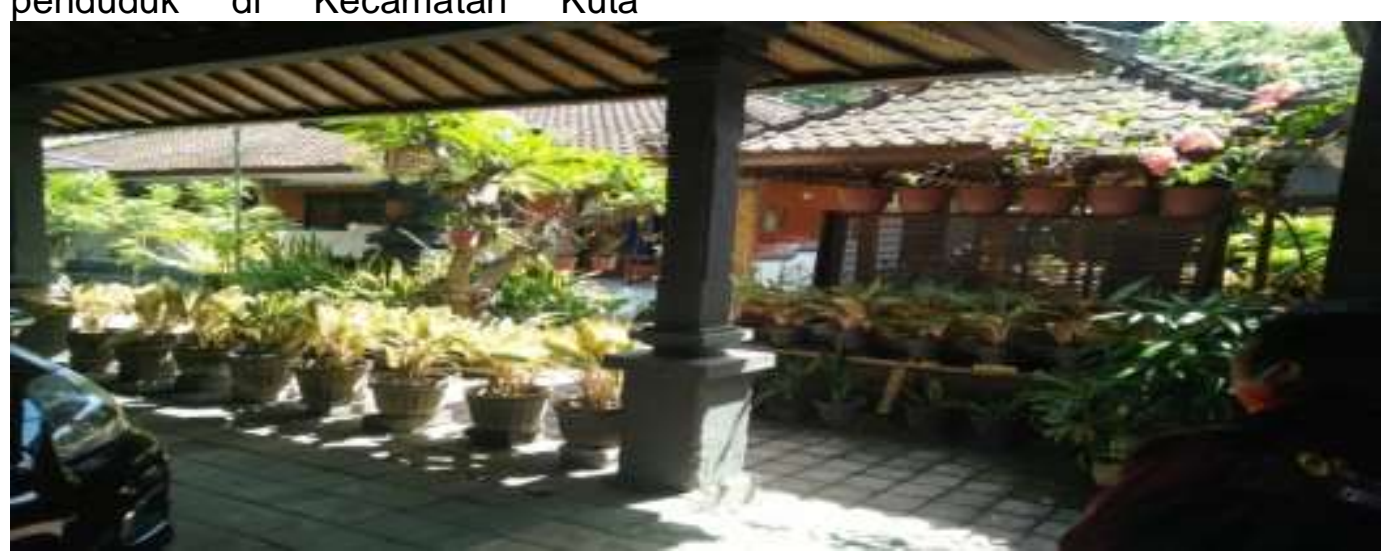

Gambar 01 Teknik Vegetasi dengan Vertikultur (JIn Pratama Tanjung Benoa)

Rendahnya penggunaan bahan organik ini disebabkan karena kesadaran penduduk yang rendah akan perawatan vegetasi dengan menggunakan pupuk. Penduduk Kecamatan Kuta Selatan juga masih sedikit yang memiliki hobi terhadap tanaman, pemakaian pupuk organik masih minim disamping juga terkendala oleh biaya. Penggunaan pupuk organik di Kecamatan Kuta Selatan juga masih terbatas dengan pupuk organik salah satunya pupuk organik Pak Oles dengan kisaran harga yang murah yaitu 1 karungnya RP.23.000. Pupuk ini juga sangat jarang digunakan sebulan 1 kali namun tidak rutin, menyesuaikan waktu santai yang dimiliki oleh penduduk

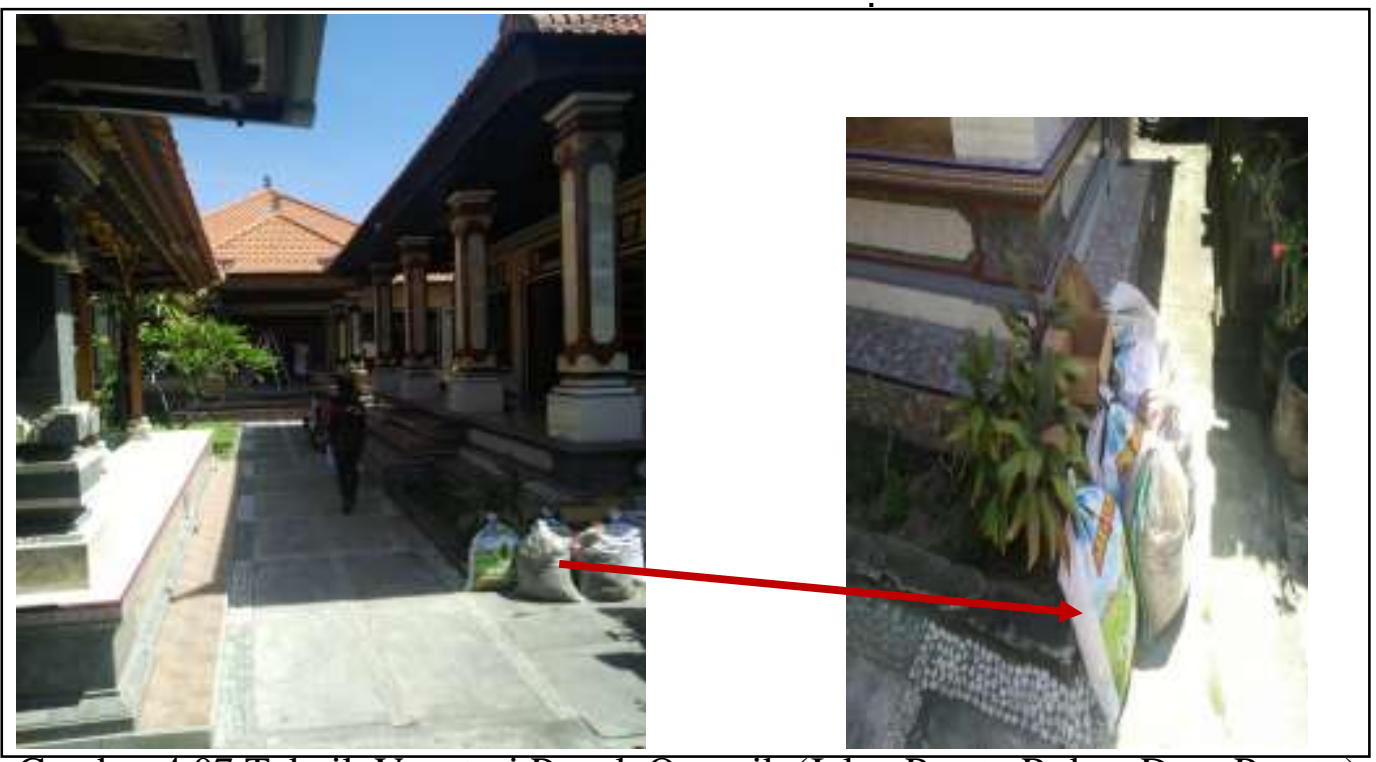

Gambar 4.07 Teknik Vegetasi Pupuk Organik (Jalan Peratu Ruken Desa Pecatu) 
Teknik Kimia

Dalam penelitian ini teknik kimia dapat dilihat dengan tiga indikator yaitu jenis bahan kimia yang digunakan, pemakaian bahan kimia dan pengaruh penggunaan bahan kimia.

Hasil penelitian menunjukkan teknik kimia di Kecamatan Kuta Selatan tidak menggunakan bahan

kimia. Rendahnya penggunaan bahan kimia ini disebabkan karena Teknik Mekanik

Teknik mekanik dapat dilihat dengan tiga indikator yaitu, ketersedian sumur resapan, kedalaman sumur resapan dan fungsi sumur resapan.

Hasil penelitian menunjukkan bahwa penerapan teknik mekanik terbesar di Tanjung Benoa. Penduduk yang menerapkan teknik mekanik untuk kedalamannya hanya mampu 5 sampai dengan 6 meter, padahal kedalaman yang baik untuk sumur resapan yaitu 8 meter. Fungsi dari sumur resapan yang dimiliki penduduk Kecamatan Kuta Selatan juga hanya berfungsi pada musim hujan.

Rendahnya penggunaan teknik mekanik ini disebabkan karena minimnya pengetahuan penduduk di Kecamatan Kuta Selatan. Biaya kesadaran penduduk yang rendah akan perawatan vegetasi dengan menggunakan bahan kimia. Penduduk Kecamatan Kuta Selatan juga masih sedikit yang memiliki hobi terhadap tanaman, sehingga pemakaian bahan kimia juga masih minim disamping juga terkendala oleh biaya.

untuk pembuatan sumur resapan di Kecamatan Kuta Selatan juga tergolong mahal, maka banyak penduduk yang tidak mampu membuat sumur resapan.

Dibandingkan dengan penelitian sebelumnya, penelitian ini memiliki persamaan dengan penelitian yang dilakukan oleh Mery Riastika (2012). Hasil penelitian menunjukkan bahwa pengelolaan airtanah berbasis metode konservasi dengan teknik vegetasi, kimia dan mekanik ini sudah diterapkan, namun belum maksimal. Teknik vegetasi ketersedian lahannya memiliki vertikultur, teknik kimia tidak semua penduduk menggunakan dan teknik mekanik ini masih sedikit yang menerapkan dengan kedalaman yang belum mencapai 8 meter, sehingga tidak memiliki pengaruh

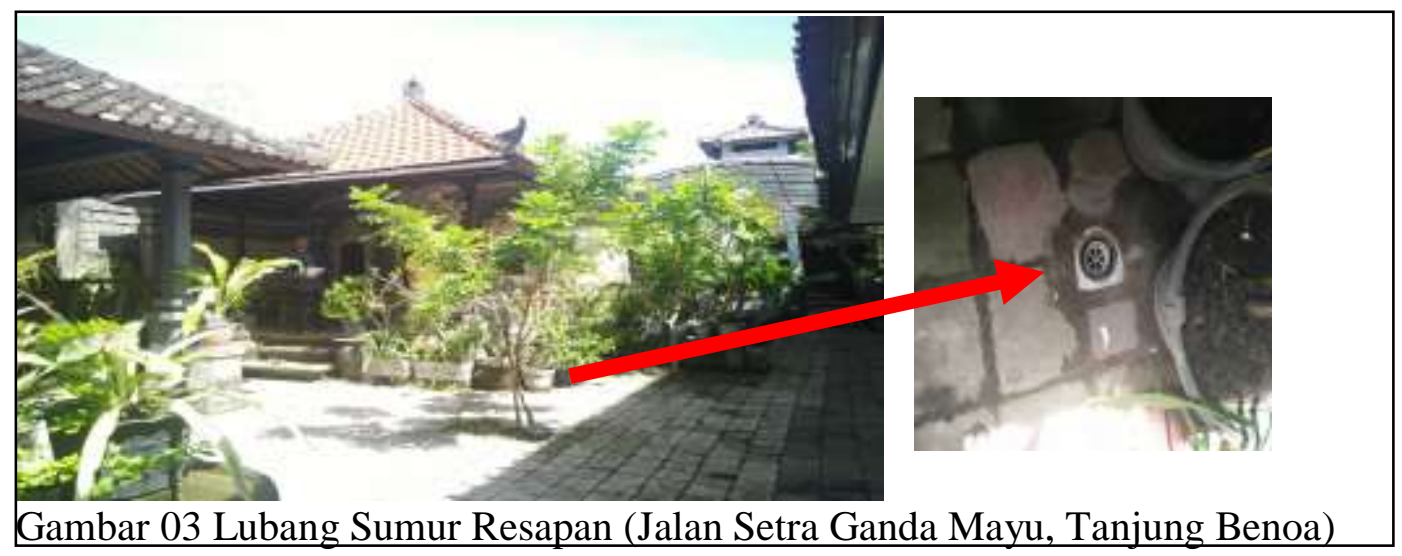

Kendala dalam Pengelolaan Airtanah Berbasis Metode Konservasi
Kendala-kendala pengelolaan airtanah berbasis metode konservasi, baik itu kendala ekonomi, kendala kelembagaan dan 
juga kendala teknologi. Hasil penelitian menunjukkan bahwa terdapatnya kendala-kendala dalam pengelolaan airtanah berbasis metode konservasi yang diterapkan di Kecamatan Kuta Selatan.

Kendala-kendala dalam pengelolaan airtanah adalah alasan utama yang menghambat penerapan pengelolaan airtanah berbasis metode konservasi. Hal ini dapat dilihat berdasarkan kendala yaitu:

\section{Kedala Ekonomi}

Kendala ekonomi di Kecamatan Kuta Selatan dapat dibedakan menjadi yaitu biaya pembelian dan juga biaya perawatan. Hasil penelitian menunjukkan bahwa kendala ekonomi merupakan kendala utama, untuk pembelian tanaman dan pupuk masih sangat redah. Rendahnya biaya untuk teknik vegetasi, teknik kimia dan teknik mekanik dapat disebabkan oleh banyaknya kebutuhan hidup sehari-hari yang harus dipenuhi

sehingga biaya untuk pengelolaan airtanah berbasis metode konservasi masih rendah. Penduduk Kecamatan Kuta Selatan dalam pembelian tanaman sangat jarang dilakukan yaitu lebih dari 12 bulan membeli tanaman, kebanyakan penduduk mendapatkan tanaman dengan cara mengambil tanaman di tempatnya bekerja atau nyetek dari tetangga, hal ini pun tidak rutin.

Rendahnya biaya pembelian tanaman dan perawatan yang dikeluarkan oleh penduduk Kecamatan Kuta Selatan, disebabkan karena alasan untuk penghematan pengeluaran dan kurangnya ketelatenan atau hobi untuk menerapkan khususnya teknik vegetasi. Bantuan vegetasi dan bahan kimia di Desa Pecatu juga tidak rutin dilakukan hanya beberapa kali pernah mendapatkan bantuan tanaman dan bahan kimia yang diprogramkan oleh subak. Sedangkan Tanjung Benoa dan Beno tidak pernah mengadakan bantuan.

\section{Kendala Kelembagaan}

Parameter yang dapat dilihat dalam kendala kelembagaan yaitu partisipasi pemerintah baik itu dengan mengadakan lomba apotik atau menetapkan peraturan yang jelas terkait pengelolaan airtanah. Hasil penelitian menunjukkan kelembagaan Desa Pecatu aktif dengan mengadakan lomba apotik yang dilakukan 5 tahun sekali, namun tidak rutin diadakan lomba dan juga ada masyarakat yang tidak mengikuti lomba apotik "Rumah sehat".

Tanjung Benoa dulunya pernah mengadakan lomba namun tidak rutin dilaksanakan. Kelurahan Benoa kelembagaannya tidak aktif, sehingga tidak pernah mengadakan lomba untuk apotik sehat.

Himbauan pemerintah untuk menerapkan teknik vegetasi, teknik kimia dan teknik mekanik di Kecamatan Kuta Selatan tidak mewajibkan penduduknya menerapkan pengelolaan airtanah berbasis konservasi. Dapat disimpulkan kurangnya partisipasi dan perhatian pemerintah daerah dalam menerapkan pengelolaan airtanah berbasis metode konservasi. Kurangnya partisipasi pemerintah dalam pengelolaan airtanah di Kecamatan Kuta Selatan disebabkan kurang aktif pemerintah daerah untuk membangun Kecamatan Kuta Selatan dalam pengelolaan airtanah.

\section{Kendala Teknologi}

Parameter yang dilihat dalam kendala teknologi yaitu teknologi perawatan vegetasi, teknologi kimia dan teknologi perawatan mekanik. Hasil penelitian menunjukkan bahwa masih sedikitnya kepemilikan teknologi vegetasi dan tidak 
memilikinya teknologi pembuatan pupuk dan perawatan teknologi mekanik.

Minimnya kepemilikan teknologi perawatan vegetasi, pembuatan bahan kimia dan perawatan mekanik disebabkan kurangnya kesadaran penduduk dalam hal perawatan sehingga tidak memiliki teknologi. Biaya untuk pembelian teknologi dan biaya perawatan untuk teknologi juga masih tinggi sehingga penduduk enggan untuk memiliki teknologi.

\section{SIMPULAN DAN SARAN}

Kualitas airtanah di Kecamatan Kuta Selatan yang diteliti di 2 Kelurahan dan 1 Desa, dengan 8 parameter yang terdiri dari parameter fisik dan kimia adalah tergolong tinggi. Namun terdapat dua parameter yang melampaui baku mutu. Parameter-parameter tersebut diantaranya parameter fisik (bau), parameter kimia (kesadahan).

Bentuk pengelolaan airtanah berbasis metode konservasi di Kecamatan Kuta Selatan terbesar adalah teknik vegetasi, rata-rata penduduk Kecamatan Kuta Selatan mengunakan teknik vegetasi memiliki vertikultur dengan luas vegetasi yang dimiliki sangat sempit hanya seluas kurang dari $2 \times 1$ meter sampai dengan $3 \times 2$ meter, dan tanaman yang mendominasi yaitu tanaman hias dengan variasi tanaman yang dimiliki penduduk berjumlah 3 sampai dengan 6 tanaman. Kondisi vegetasi yang dimiliki penduduk Kecamatan Kuta Selatan terawat, tetapi tidak tertata dengan baik dan bersih.

Kendala utama dalam penerapan pengelolaan airtanah di Kecamatan Kuta Selatan adalah kendala ekonomi. Kendala ekonomi meliputi biaya perawatan vegetasi
Dibandingkan dengan penelitian sebelumnya, penelitian ini memiliki persamaan dengan penelitian yang dilakukan oleh Puji Pratikyono (2011). Hasil penelitian menunjukkan bahwa terdapat kendala-kendala dalam penerapan pengelolaan airtanah berbasis metode konservasi sehingga penerapan pengelolaan airtanah berbasis metode konservasi tidak maksimal.

(pembelian tanaman dan bahan kimia) dan biaya perawatan mekanik.

Penduduk Kecamatan Kuta Selatan, Kabupaten Badung diharapkan tidak menggunakan airtanah sebagai sumber air minum, karena terdapat parameter yang melampaui baku mutu yang sudah ditetapkan.

Penduduk Kecamatan Kuta Selatan, Kabupaten Badung diharapkan menerapkan metode konservasi tanah, dengan teknik vegetasi, teknik kimia dan mekanik. Pengelolaan airtanah berbasis konservasi ini bermanfaat untuk peningkatan ketersediaan airtanah.

Perlu adanya partisipasi dari Pemerintah Kecamatan Kuta Selatan dalam membantu penduduk menerapkan pengelolaan airtanah berbasis konservasi, misalnya bantuan tanaman atau pupuk secara merata kepada penduduk. Pemerintah Kecamatan Kuta Selatan juga diharapkan berpartisipasi dalam mengembangkan Kecamatan Kuta Selatan misalnya aktif mengadakan lomba apotik sehat dan menetapkan aturan-aturan yang tegas dalam pengelolaan airtanah. 


\section{DAFTAR PUSTAKA}

Haris, 2015. "Pemanfaatan Bak Resapan Dan Biopori Sistem Guna Mengatasi Masalah Genangan Air" Jurnal Teknik, Vol 8 (3): 186-194

Puji, Pratiknyo. 2011. "Program Pengelolaan Air Tanah".Jurnal Lingkungan, Vol 5 (3): 125

Riastika.M. 2005. Pengelolaan Air Tanah Berbasis Konservasi Recharge
Boyolali. Jurnal IImu Lingkungan, Vol 9 (2): 87-97.

Sundra. 2012. Kualitas Air Bawah Tanah Di Wilayah Kuta Selatan Kabupaten Badung. Jurnal lingkungan, Vol 2 (10):477-491

UPT Balai Laboratorium Kesehatan Provinsi Bali tahun 2017. 